\title{
Latest Perspectives on Global Renewable Energy Policies
}

\author{
Anis Radzi • Peter Droege
}

Published online: 5 July 2014

(C) Springer International Publishing AG 2014

\begin{abstract}
Renewable energy policies play a critical role in the success of replacing incumbent energy supply networks based on fossil fuels and nuclear power with renewable sources of energy from solar, wind, water, geothermal, and biomass. We conducted a focused literature review on energy articles discussing the governance of renewable energy, with the goal to understand the latest research trends, questions, and issues on this topic. One prominent scientific database on energy provided the starting point for analysis, with our search period limited to 2013-early 2014. The review did not attempt to provide an exhaustive analysis but rather to provide a quick snapshot of pertinent questions in order to distill specific issues. The thematic analysis of the literature revealed the following trends: addressing policies in developing countries, resolving inconsistencies between national, regional, and local policies, managing the impact of political agendas, developing techniques to revise energy policies, understanding the spatial implications of renewable energy, and reviewing the levels of acceptance by different stakeholders.
\end{abstract}

Keywords Renewable energy · Energy policy · Governance · Spatial planning

\section{Introduction}

Policies on renewable energy sources (RES) have been developed to include more stringent measures to promote and mandate their generation, distribution, and use. These are aimed to adapt to market fluctuations, rapidly improving renewable energy technologies and shifting social perceptions of their environmental and socio-economic impacts. While

\footnotetext{
A. Radzi $(\bowtie) \cdot$ P. Droege

Universität Liechtenstein, Fürst-Franz-Josef-Strasse, Vaduz 9490, Liechtenstein

e-mail: anis.radzi@uni.li

P. Droege

e-mail: peter.droege@uni.li
}

villages, towns, and cities around the world see merit in introducing or maintaining these policies, others remain unmoved by the need to shift local and regional supplies from usually imported, fossil, or nuclear sources, to renewable energy. Latest reports by the Intergovernmental Panel on Climate Change (IPCC) and Renewable Energy Policy Network for the 21st Century (REN21) show, however, that the transition is taking place, as evident in the increasing number of local and national government policies on energy efficiency and renewable energy. The latest literature over the past year (2013-2014) has shown that these policies have now reached a stage of maturity whereby a suitable framework or methodology is needed for governments that are involved and active, in order to critically review and adapt them.

\section{Major Themes and Viewpoints}

This paper provides an overview of the major research trends with regard to renewable energy policy. The following section provides the main body of discussion and outlines each theme in relation to the approach and focus of the selected articles. The discussion is followed by some conclusive remarks.

1. Addressing regional challenges in the developing countries

The barriers to the implementation of RES policies remained consistent amongst the developed and developing countries. Most articles found in the last year have focused largely on developing countries, namely those in Africa, the Indian subcontinent, and Asia, particularly China.

Mohammed, Mustafa, and Bashir (2013) reviewed the status of renewable energy development and use in subSaharan Africa and found that the challenges there related to cultural constraints, educational backgrounds, unstable economies, poor financial support, low foreign investment, weak policies and capacity building, and absent pilot demonstrations [1]. Kaunda (2013) noted that in Malawi, the country's 
economic and environmental challenges were directly attributed to its weak energy situation. The implementation of small-scale hydropower systems were, for example, affected by a paucity of economic, technical, and awareness of the technology despite its large hydro energy potentials [2]. Alfaro and Miller (2014) affirmed in their research the large potential of RES even in rural residential areas of Liberia. However, decentralized renewable energy still faced institutional challenges, a lack of available credit, as well as high capital costs of installations and other upfront fees [3]. In other areas of Africa, high costs were compounded by limited access to technical expertise and financial support. Ahlborg and Hammar (2014) found that in Tanzania and Mozambique, rural electrification from off-grid systems faced difficulties in gaining access to human capital, particularly in the simpler practical challenge of installing electric equipment in traditional buildings. There was a very high degree of planning and donor dependency; resulting problems were compounded by minimal interest from the private sector: in turn, largely a response to the weak rural markets for RES. The poor understanding of culturally differentiated practices - for example, solar cookers that did not function in the evening when cooking was largely undertaken - was an example for essential and basic practices not being understood in the implementation of systems. The negative association of off-grid RES systems with 'diesel' off-grid systems was another dampening effect due to their high-cost and pollutive impacts, which was also not fully considered in implementation [4]. Gurung, Karki, Cho, Park, and Oh (2013) found that in Nepal the barriers to RES implementation also related to poor coordination among the donors in national programs. In addition, the lack of long-term financing schemes, poor private sector participation, inadequate institutional structure, and the weak purchasing power of rural communities have all posed serious challenges to governments and communities [5].

\section{Maintaining consistency between governance levels on RES policy}

The latest research indicated that the failure and/or ineffectiveness of RES policies were largely attributed to the lack of coordination between local and national policies, whereby one would restrict or even negate the other.

Zheng, Li, and Zhao (2013) saw that the failure to formulate consistent local and national policies was a challenge for local governments in China since municipalities have preferred to focus on local policies that only benefit their community, to the detriment of their regional neighbors - who often showed a lack of concern [6]. Diaz and Maso (2013) found that in this case, what was still needed in China was the coordination of actors responsible for energy governance, alongside the investment in the research and development (R\&D) of energy efficiency and renewable energy that did not discriminate between jurisdictions [7]. Such differences in priorities, particularly between the central and local governments, can also be seen in the export-oriented focus of China's manufacture and promotion of renewable energy technologies (RETs). Fang and Li (2013) reviewed China's Renewable Energy Law in relation to the R\&D of renewable energy technologies and sources and found that despite the national government's best efforts, this overriding focus on exports has resulted in the low uptake of renewable energy systems in the country itself. The overall share remains low despite the rapid increase of domestic installations. R\&D has focused on exporting technologies rather than improving local systems, particularly the energy grid, which has not been able to distribute the renewable electricity sourced from areas of high solar irradiation to distant urban centers [8].

There were other examples of the policy inadequacies, which had translated into organizational inefficiencies in RET implementation. Raha, Mahanta, and Clarke (2014) noted that in Assam, NE India, the National Biogas and Manure Management Programme (NBMMP) initiated by the central government did not include education and awareness programmes, and had left local non-governmental institutions (NGOs) or other stakeholders to take on the installation and the training of users themselves, typically women who would feed, operate, and maintain the household biogas systems. This also has resulted in biogas plants not being used to their fullest capacity due to the lack of knowledge and understanding of the technology. The NBMMP is a top-down system linking central, state, and private contractors to deliver biogas to rural households. Engagement with community stakeholders, farmer cooperatives, banks, research institutions, and NGOs was absent, with no provisions to enable and sustain the scheme at the community level [9].

Indeed, Khare, Nema, and Baredar (2013) revealed that in India, centralized coordination has been difficult, especially in the light of the existence of no single comprehensive policy statement for RES in the country, despite the large numbers of ministries, agencies, institutes, and stakeholders who have some interest in RES or energy in general. One particular concern noted was the lack of coordination between these entities in relation to the acceptance of wind power projects, as some groups have awarded project approval on the basis of national gazetted schemes, while others have not or are yet to recognise these schemes. This has caused delays in gaining permission for projects granted through competitive bidding and have therefore caused some financial penalty for the developer [10]. The number of actors involved is an issue, as Dulal, Shah, Sapkota, Uma, and Kandel (2013) found that for the central governments of Asia, the challenge to renewable energy diffusion lies in the "large number of redundant transactions with a multitude of government agencies, lack of transparency in the energy supply and transportation contracts, inadequate provision of information on permitting and 
legal appeal procedures, presence of contradictory clauses regarding the responsibility to extend the electricity networks, and intimidation and pressure by labor unions" (p. 309). All of these factors would impact the confidence of investors in RES.

Despite the initiation of entities responsible for the implementation or promotion of RES, there was also no guarantee of their long-term existence or effectiveness since these have depended greatly on continual government budgets for RES and available scientific capacity [11]. In Pakistan, Awan and Khan (2014) reported that the central government created two organizations to promote RES in Pakistan: the Pakistan Council for Renewable Energy Technology, started in 2001 to ensure development of renewable energy projects in the country, and the Alternative Energy Development Board (AEDB), created in 2003 to join efforts. However, both had failed to achieve any success due to poor technical management and weak financial resources [12].

\section{Managing political influences}

The impact of political goals and processes has become a major factor on the longevity of RES policies. In particular, key issues are related to annual budgetary cycles, policy 'flip-flops', and political connection, interference, partisanship, and culture.

White, Lunnan, Nybakk, and Kulistic (2013) found that in Norway the decisions made annually on government budgets have created an uncertainty for the implementation of RES regulations - for example, the stipulation that all diesel sold must contain $2.5 \%$ biodiesel. They argued that policy flipflops "will shake investor confidence and that no one will take the government seriously when it promises industry assistance" (p. 103) [13]. Zhang, Li, Zhou and Zhou (2014) concluded that in China, while government subsidies have been a positive influence on financial performance of wind and solar companies, political connections have reduced the effectiveness of subsidies [6]. Uddin and Taplin (2009) noted that in Bangladesh the nature of organizational inefficiency was primarily shared between an intrinsic inefficiency of public organizations and political interferences [14]. Fowler and Breen (2014) found that when adopting financial incentives for renewable energy, state governments in the USA were influenced by political factors related to economics when it came to tax incentives, and culture when it came to grants and loans programs [15]. Taking the terms coined by Elazar (1984), they argued that 'moralistic' governments are more willing to adopt financial incentives than 'individualistic states'. They founded that "as states develop economically, they are no longer constrained by struggling to provide the most basic of services and are able to take on more progressive functions" (p. 78). They concluded that "culture, partisanship and economics played an important but variable role in financial incentive adoption" (p. 83) [16]. Indeed, political ambition plays a considerable hand in driving certain RES projects. Ahlborg and Hammar (2014) found that in Tanzania and Mozambique, rural electrification from off-grid RES were driven by political ambitions based on expected growth of demand, as well as local initiatives by industries or churches [17].

4. Reviewing and adapting the next generation of RES policy

Today's RES policies have largely been the result of efforts of pioneering governments who have dared to formulate policies on RES during a period when most around the world have not. They have played an important role in not just setting a precedence and positive example, but in improving RES policies that could now be adopted by governments that have yet to consider RES regulation. Indeed, within the last few years, RES policies have reached a stage where their evaluation has become critical. Researchers are now searching for ways to review, amend, adapt, integrate, or replace existing policies that respond better to the latest economic, social, and technological changes. It may require the consideration of new evaluating tools or frameworks, which many researchers have lately focused upon on.

Connor, Bürger, Beurskens, Ericsson, and Egger (2013) found that "attention must be paid as when one instrument should give way to another and when a technology should be abandoned" (p. 14) when they explored policies for heat from renewable sources, such as the use obligations of the Merton Rule or the Barcelona Ordinance. [18] Trümper, Gerhard, Staatmann, and Weinmann (2014) noted that the relationship between energy policy and energy-economic aspects will also need to be fully understood. There needs to be "an approach that monitors the interaction between funding and regulation elements at different stages of the value chain" (p. 169) [19]. There are proposals for a new RES market design to ensure the necessary investment incentives for the energy system into the future. These would take into better consideration grid usage, capacity premiums, load profiles, storage incentives, or simply the redesign of the renewable energy feed-in law.

Pietrosemoli and Monroy (2013) proposed the need for a knowledge management process in order to learn from and adapt actions in the sustainable construction of renewable energy projects. The added dimension of constructing to achieve sustainability goals has manifested itself in project planning and monitoring approaches with the aim to "prevent and reduce technical, environmental or financial risks and sustain the adequate management of all the resources involved" (p. 689) [20]. Calvert, Pearce, and Mabee (2013) proposed the introduction of geo-information infrastructure to also help build institutional capacity in reviewing decision-making in energy 
planning [21]. Stokes (2013) reaffirmed the need for continual review of energy policies in a review of feed-in tariffs in Ontario, Canada, "as governments attempt to contain the overall cost and acceptability of the policy, and investor stability, a constantly heralded critical factor for policy effectiveness" ( $p$. 499) [22]. Refinement is necessary over time to address opposition concerns, for example, through community supported or owned power projects, consulting with communities early and actively, using mediators, or pursuing collaborative work across jurisdictions. Menegaki (2013) highlighted the need for the management of RES that keeps "RES industry consumers and producers interested to participate in the transaction" (p. 346) [23]. For industry, it is the guarantee of continuous demand of RES technology. For investors, it is the high-as-possible producer surplus. For consumers, it is the maintenance of low prices.

For Zheng, Li, and Zhao (2013), the speed of renewable energy technology development has become a real challenge for policymakers. They need to determine whether they will keep to traditional solutions that can make use of the most cost-effective technology, which may mean discounting expensive, yet more innovative technologies [24]. Indeed, some have argued that resorting to higher-cost technologies may lead to dangerous policies" (De Castro, Mediavilla, Miguel, and Frechoso, 2013 p. 834). In their examination of the technical and sustainable limits of the global solar electric potential, they concluded that maximum potentials do exist, particularly for biofuels, wind, and solar power, but its overestimation can lead to an overemphasis on investment of expensive infrastructure that may not be cost-effective due the high price of the electricity it produces, not to mention the underestimation of the savings and efficiency measures (De Castro et al., 2013) [25]. This assertion flies in the face of the latest reports by the IPCC (2011) that there is no such technological limit [26]. Notwithstanding the debate between old and new technologies in relation to their cost-effectiveness, Blenkinsopp, Coles, and Kirwan (2013) have, on the more practical level, preferred to highlight the need for an increased focus on low-cost, renewable energy technologies that are easy to maintain by the community, coupled with educational schemes to highlight the benefits of its use. This was a significant recommendation in their survey of rural communities in the Indian state of Maharashtra [27].

Whether old or new, low or high-cost, renewable energy technology installations should also be distinguished and handled differently by support mechanisms. Hong, Lund, Mathiesen, and Möller (2013) wrote "...policy-makers need to establish long-term energy efficiency policies and set clear standards, targets and timetables for specific sectors especially energy intensive sectors. ... long-term plans and stable promotion policies for renewable energy technologies are very important for renewable energy industry to achieve technological learning and the economies of scale" (p.277) [28].
Meanwhile, it is important that changes are not too frequent and that any amendments would attempt to anticipate any future changes. For White, Lunnan, Nybakk, and Kulistic (2013): "The literature favours consistent and ex ante policy approaches compared with frequent changes in policy or an ex post approach in which policy is chasing the current state of affairs" (p. 103) [13].

\section{Embracing the spatial implications}

The need for space to generate renewable energy requires its management through land-use planning and governance measures, particularly in order to address the competition for land between crops for food and crops for energy, and the environmental impact of energy cropping on biodiversity. Within the literature of the past year, there was very little emphasis by researchers on understanding such spatial implications of managing RES for professionals in spatial planning.

Pedroli et al. (2013) examined the impact of EU 2020 targets on bio-cropping on biodiversity and found that some energy crops are more sustainable than others but that their actual impact remains highly dependent on regional circumstances [29]. Land conversion for energy cropping is an issue and requires further research. Lupp, Steinhauesser, Starick, Gies, Bastian, and Albrecht (2014) argued that regulation is needed for the cultivation of energy crops, in particular to support farmers in opting for less harming crops and promoting alternatives. The point is to focus on good farming practices rather than relying on the goodwill and expertise of farmers and foresters. The amendment of the regional plan that integrates an evaluation of the impacts of land use patterns was recommended [30]. Others also argued for regulating RES that coordinates their generation in spatial terms. Bao and Fang (2013) in their spatial analysis of renewable energy development in China concluded: "Besides some technical, economic and policy issues, an integrated spatial coordination and a scientific environmental cognition are two important factors for it “ (p. 473) [31]. Zheng, Li, and Zhao (2013) also saw that policies need to catch up with the distributive, decentralized nature of renewable energy sources [24]. For Mondol and Koumpetsos (2013), by categorizing the Greek islands based on energy reduction cost, heating days, and the proportion of old buildings, found that action plans and implementation strategies could be proposed for residential nongrid communities [32].

Some researchers have focused on proposing new concepts as a communicative tool in the spatial planning of RES. For Blaschke, Biberacher, Gadocha, and Schardinger (2013), the notion of an "energy landscape establishes a link between physics-based views on energy commodities and their spatial footprints on the one hand and the 'energy landscape' concept and how people think about geographic space on the other hand" (p. 14). This intuitive spatial planning 
concept is designed to stimulate interdisciplinary discussion between physicists, energy experts, and spatial planners. Although they could not offer any guiding principles to the design of this energy landscape, they showed the significance of size, shape, number of sites, and their spatial positioning. The use of geographic information systems (GIS) was found to only permit the determination of optimal spatial solutions and could not differentiate between good and bad designs of energy landscapes [33]. This is especially pertinent as the renewable energy generation of available lands become more distinguishable. For instance, Milbrandt, Heimiller, Perry, and Field (2014) found that in the United States, the annual consumption of $4 \mathrm{PWh}$ of electricity in 2011 could be capably produced on marginal lands just from photovoltaics (PV) or concentrated solar panels (CSP) [34]. Marginal lands are areas that are underused, have low cultivation potential, little economic worth, and changing development capacity. They include lands that are abandoned, distributed, underutilized, degraded, or wasteland. Utilizing such lands can alleviate the pressure from competition for valuable land resources.

\section{Extending the individual and social acceptance}

The emergence of the consumer as a generator of renewable energy also requires facilitation and management by governments. Social acceptance continues to be an important consideration in the promotion of RES. However, rather than the mere study of how to increase acceptance, researchers now focus on understanding the level acceptance of particular actors, and ascertain how their contribution may differ and impact on others, thereby developing a momentum for RES acceptance. The governance of specific actors is called for, mirroring the governance of the different types of RETs. The study of community mobilization in RES projects that focuses specifically on the initiator, leader, promoter, and mediator is needed, as an element of trust was found to be essential throughout the entire implementation process. This is in order to create an inclusive environment that gives all members of society the choice to participate in RES projects. Meanwhile, communities still expect governments to lead and even do more with RES implementation, which shows that both topdown and bottom-up approaches are necessary depending on regional circumstances.

Ruiz-Romero, Colmenar-Santos, Gil-Ortego, and MolinaBonilla (2013) concluded that in Spain, "The users will become vital power agents, not only because they may participate in preservation and efficiency measures but also because they will be part of an increasingly more distributed power generation network. Hence, a new player will participate in the energy scenario as a Pro-consumer" ( p. 363) [35]. Stigka, Paravantis, and Mihalakakou (2014) noted that it is useful to focus on the social acceptance of RES, but in particular the connection of household characteristics to public preferences to improve electricity services, designing better energy policies and increasing the demand for reliable energy sources [36]. Fast (2013) employed Habermasian discourse analysis to study the ways in which citizens understand and negotiate renewable energy developments in the Eastern Ontario Highlands, which revealed that issues there concerned unequal access to incentive programs and the perceived position of the powerful seasonal resident population [37].

An integrated participatory energy policy is essential in the long run. Wiedman and Beach (2013) wrote that the harnessing of individual, community, and business interest in distributed generation (DC) “... will require the development of smart, customer-focused policies that provide a stable and certain environment in which customers can make informed investments in DG systems, and incentives to encourage utilities to integrate DG resources into their planning on the same basis as investments in large-scale generation or the delivery infrastructure" (p.103) [38]. In their analysis of renewable energy tariff policy in China, Ming, Ximei, Na, and Song (2013) proposed that it will become "necessary for scholars to research how to form a perfect comanagement mechanism that government, market and public are all involved in" (p.270), and that “... the related institutional innovation and market-oriented reforms should be introduced in order to create a good environment for large-scale exploitation and utilisation of renewable energy and industrial development, which can promote a omnidirectional, diversified and large scale development for renewable energy..." (p.271) [39].

Other integrative energy frameworks are manifested in community organizations especially set up to implement certain renewable energy technologies, such as solar community organizations (SCO), which are formal or informal organizations or citizen groups explicitly designed to encourage the adoption of residential rooftop solar PV. Noll, Dawes, and Rai (2014) evaluated the SCOs in the United States from 19722012 and their effect on the adoption of residential PV, concluding that "shock" events had catalyzed grassroots environmental action (for example, concerns for the environment, oil crises, global warming, etc.), and that trust networks were key aspect of SCOs. For example, these networks are able to inform and influence through longstanding linkages with key individuals in local communities, links to government, NGOs, solar companies and others, and rely on "SCO members as trusted opinion leaders with a history of commitment to the local community" (p. 330) [40]. Indeed, implementation needs to involve all parties at various scales of renewable energy technology.

Li, Birmele, Schaich, and Konold (2013) showed that community commitment in undertaking small-scale projects was essential. The example of Freiamt in the southern German state of Baden Wurttemburg, which had achieved $100 \%$ 
power production from RES, showed that community attitude, character, motivation, and pride were instrumental to carrying out projects that benefited the entire community. They concluded that bottom-up processes were best for rural communities, while top-down approaches were suggested to be more appropriate for urban communities, but still depending on the specific regional context [41]. Similarly, Sovacool (2013) found in an analysis of eight public-private renewable energy partnerships around the world that "the pro-poor publicprivate partnership model [5Ps] of renewable energy diffusion can be effective a meeting national and programmatic targets for electrification and access, sometimes ahead of schedule and below cost" (p. 191). The 5Ps were considered to occupy a "fruitful "middle ground" between commercial private sector projects, focused primarily on profit; and public sector projects, focused primarily on enhancing access" (p. 191) [42].

It is interesting to note that governments were still relied upon to hold the overall responsibility for continual efforts in renewable energy generation, despite the emphasis by most researchers on the contribution of the rest of society in optimizing its production. Moula, Maula, Hamdy, Fang, Jung, and Lahdelma (2013) found in their survey of 50 people on the acceptability of renewable energy technologies in Finland that most believed that the public sector should not only take the first step towards renewable energy production, but they also expected more from the sector [43]. This expectation implies a certain level of trust to be built in governments on the implementation and promotion of renewable energy technologies. Liu and Shiroyama (2013) argued that in China, the macrolevel environment was most suitable for the development of the solar PV industry. Since it is a long-term process, the central government was in the best position to find the best governance method to manage the transition that allows "an ongoing process of doing by learning" (p. 790). They highlighted new efforts to implement demonstration programs at the local level in order to reform the current regime in a bottom-up manner. However, they argued that such programs need to be regarded as "protected spaces" for a renewable energy implementation, in that, within these spaces, the households, grid company, PV manufacturers, and government can all adapt to changes in the system [44]. It becomes a learning philosophy of learning by doing or learning by using. Lo (2014) further explained that these pilot programs in China encourages local government to go beyond minimal compliance, and develop long-term, low-carbon plans, instigate institutional reform, develop policies for buildings and transportation, create carbon accounting and management systems, and promote low-carbon lifestyles. It works in tandem with a target responsibility system (TRS) to best stimulate local innovation. A TRS deals with rules on job assignment, performance appraisal, and remuneration, however, it does not limit consumption or set renewable energy targets [45].

\section{Conclusion}

Current research on renewable energy policies reveals that barriers to their implementation are related to high up-front costs, low investment, lack of incentives, poor technical capacity, and low levels of awareness of renewable energy technologies. In addition, the growing challenge has been the lack of coordination between central and local policies, and between the numerous entities with vested interests in RES. Managing political interests and budgets will have a great impact on the likelihood of policy implementation and continuation. Those governments that have had RES policies in place today face a new challenge of finding ways to effectively review and adapt the next generation of RES policies, as researchers have discovered. This includes addressing the spatial implications of managing land-uses for renewable energy generation. It also includes a closer understanding of cultural implications and social acceptance with regards to the role of specific sectors, and their capacity to leverage support in others. However, even despite a rising awareness that the involvement of all sectors of society is imperative in the transition to renewable energy, the expectation remains that government ultimately leads the implementation of renewable energy projects.

\section{Compliance with Ethics Guidelines}

Conflict of Interest Anis Radzi and Peter Droege declare no conflicts of interest.

\section{References}

1. Mohammed YS, Mustafa MW, Bashir N. Status of renewable energy consumption and developmental challenges in Sub-Sahara Africa. Renew Sust Energ Rev. 2013;27:453-63. A review of 42 countries in Sub-Sahara Africa revealed challenges related to cultural practices, educational background, weak economies, low financial investment or support, untenable policies on renewable energy and absence of technologies and technical capacities, even despite the presence of a number of regional organizations set up to guide renewable energy implementation.

2. Kaunda CS. Energy situation, potential and application status of small-scale hydropower systems in Malawi. Renew Sust Energ Rev. 2013;26:1-19. Document reviews and interviews with energy experts and government officials responsible for renewable energy in Malawi discussed the effects of a poor economy, weak private sector involvement and general engineering challenges, installing growth of small-scale hydro systems in the country.

3. Alfaro J, Miller S. Satisfying the rural residential demand in Liberia with decentralised renewable energy schemes. Renew Sust Energ Rev. 2014;30:903-11. By conducting a sensitivity analysis on levelized costs of electricity, expected electricity demand, and total expected capital costs, a clearer picture of the cost-effectiveness of distributed renewable energy schemes in Liberia was gained.

4. Ahlborg H, Hammar L. Drivers and barriers to rural electrification in Tanzania and 117-124. Literature reviews and structured interviews 
with power sector actors helped identify the political drivers and logistical barriers related to systems use and maintenance. 2014.

5. Gurung A, Karki R, Cho JS, Park KW, Oh SE. Roles of renewable energy technologies in improving the rural energy situation in Nepal: gaps and opportunities. Energy Policy. 2013;62:1104-9. An analysis of the latest household energy consumption and use of RES in the rural areas of Nepal revealed a trend for replacing the traditional use of solid biomass with RES such as mini and micro hydro systems, solar, and biogas systems. However, even these are still dependent on centralized control of local energy supply networks.

6. Zhang H, Li L, Zhou D, Zhou P. Political connections, government subsidies and firm financial performance: evidence from renewable energy manufacturing in China. Renew Energy. 2014;63:330-6. An analysis of wind and solar manufacturing companies listed on the Shanghai and Shenzhen stock exchange revealed that the negative impact of political influence of the company executives had outweighed the positive effect of government subsidies.

7. Diaz P, Maso J. Evolution of production and the efficient location of renewable energies. The case of China. Energy Procedia. 2013;40:15-24. A geo-spatial multicriteria methodology was proposed to optimize the positioning of renewable energy technologies in China, which would also aid territorial planning by decision-makers.

8. Fang X, Li D. Solar photovoltaic and thermal technology and applications in China. Renew Sust Energ Rev. 2013;23:330-40. The analysis of solar photovoltaic and thermal technologies outlined a simple list of solutions to the problems facing the China's PV industry, the most important of which was to reprioritize PV R\&D for local implementation over PV R\&D for global export.

9. Raha D, Mahanta P, Clarke ML. The implementation of decentralised biogas plants in Assam, NE India: the impact and effectiveness of the National Biogas and Manure Management Programme. Energy Policy. 2014. doi:10.1016/j.enpol.2013.12.048. A survey of 60 households in Assam, India, determined that the lack of awareness meant a low adoption of biogas systems by communities, dampened by a national biogas policy that did not sufficiently focus on the promotion and delivery of energy services by the biogas market.

10. Khare V, Nema S, Baredar P. Status of solar wind renewable energy in India. Renew Sust Energ Rev. 2013;27:1-10. An overview of the development of solar and wind energy in India provided a documentary account of the potentials, regulatory conditions, and challenges to their implementation, with a brief list of actors that would be responsible to effectively drive action.

11. Dulal HB, Shah KU, Sapkota C, Uma G, Kandel BR. Renewable energy diffusion in Asia: can it happen without government support? Energy Policy. 2013;59:301-11. A review of twelve Asian and Pacific countries revealed the inadequacies of existing renewable energy policy frameworks and the lack of regulatory intervention that can address key structural barriers.

12. Awan AB, Khan ZA. Recent progress in renewable energy - Remedy of energy crisis in Pakistan. Renew Sust Energ Rev. 2014;33:236-53. An overview of the latest developments in RES in Pakistan showed a slowly growing deployment of low-tech RES systems, while regulatory commitment was indicated as being still insufficient to support its wider implementation.

13. White W, Lunnan A, Nybakk E, Kulisic B. The role of governments in renewable energy: the importance of policy consistency. Biomass Bioenergy. 2013;57:97-105. Through a literature review of the role of governments in renewable energy, combined with results from the analysis of energy policies in Canada and Norway, a discussion revealed that policy changes inevitably created an atmosphere of uncertainty for investors in renewable energy.

14. Uddin SK, Taplin R. Trends in renewable energy strategy development and the role of CDM in Bangladesh. Energy Policy. 2009;37(1): 281-9. The governance of clean development mechanisms to aid the development of renewable energy in Bangladesh created challenges related to inconsistencies in strategy and policies between different interested parties.

15. Fowler L, Breen J. Political influences and financial incentives for renewable energy. Electr J. 2014;27(1):74-84. The development of state renewable energy policies in the United States affirmed arguments that state incentives provided greater economic assistance than federal policies.

16. Elazar D. American federalism: a view from the states. 3rd ed. New York: Harper \& Row; 1984.

17. Ahlborg H, Hammar L. Drivers and barriers to rural electrification in Tanzania and 117-124. Literature survey, interviews and site observations formed the basis of study and of the drivers and barriers to rural electrification in the two African countries and found that political priorities and donor dependency were the two main factors impacting the development RES. 2014.

18. Connor P, Bürger V, Beurskens L, Ericsson K, Egger C. Devising renewable heat policy: overview of support options. Energy Policy. 2013;59:3-16. A range of financial and non-financial support mechanisms for RES-H was discussed in terms of their political feasibility and stability for industry, and concluded that these tools would be most effective when they are employed within a positive and holistic policy environment.

19. Trümper SC, Gerhard S, Staatmann S, Weinmann O. Qualitative analysis of strategies for the integration of renewable energies in the electricity grid. Energy Procedia. 2014;46:161-70. Germany's energy transition was analyzed in terms of the country's capacity to address electricity shortages and oversupplies through the planning of smart grids and energy storage systems, which would require future regulatory support from the national level.

20. Pietrosemoli L, Monroy CR. The impact of sustainable construction and knowledge management on sustainability goals. A review of the Venezuelan renewable energy sector. Renew Sust Energ Rev. 2013;27:683-91. A proposed knowledge management process was explained to better help mediate and understand the role and decisions made by different stakeholders in the implementation process of renewable energy projects.

21. Calvert K, Pearce JM, Mabee WE. Toward renewable energy geoinformation infrastructures: applications of GIScience and remote sensing that build institutional capacity. Renew Sust Energ Rev. 2013;18:416-29. The importance of GIS to aid decision-making by governments was shown in a review of ways RES can be mapped through resource inventories and graphical modelling. However, discussion led to the need to address ways to choose the right geographic scale for collecting data, and to interpret the interaction between different types of RES in order to optimize their development.

22. Stokes LC. The politics of renewable energy policies: the case of feed-in tariffs in Ontario, Canada. Energy Policy. 2013;56:490-500. Stokes explored the need to consider political implications and ways to manage opposition to RES.

23. Menegaki AN. Accounting for unobserved management in renewable energy \& growth. Energy. 2013;63:345-55. A management stochastic model helped evaluate the effectiveness of RES development and deployment, via policies on RES throughout Europe.

24. Zeng M, Li C, Zhao L. Progress and prospective on the policy system of renewable energy in China. Renew Sust Energ Rev. 2013;20:3644. A review of laws on pricing, technology, and government administration indicated that making transparent development planning of renewable energy, improving administrative policies and pricing policies, and revising technology standards would be necessary for the long-term in China.

25. de Castro C, Mediavilla M, Miguel LJ, Frechoso F. Global solar electric potential: a review of their technical and sustainable limits. Renew Sust Energ Rev. 2013;28:824-35. The political implications were discussed in light of the findings of a revised calculation on the potential of solar electricity globally that took into account future 
energy consumption and developments in renewable energy technologies.

26. Intergovernmental Panel on Climate Change (IPCC). In: Edenhofer O, Pichs_Madruga R, Sokona Y, Seyboth K, Matschoss P, Kadner S, Zwickel T, Eickemeier P, Hansen G, Schlömer S, von Stechow C, editors. IPCC special report on renewable energy sources and climate change mitigation. United Kingdom: Cambridge University Press; 2011.

27. Blenkinsopp T, Coles SR, Kirwan K. Renewable energy for rural communities in Maharashtra, India. Energy Policy. 2013;60:192-9. A survey of one rural village undertaken to determine household energy use and perceptions of renewable energy revealed that cost and reliability remains the major barriers to their wider utilization.

28. Hong L, Lund H, Mathiesen BV, Möller B. 2050 pathway to an active renewable energy scenario for Jiangsu province. Energy Policy. 2013;53:267-78. The use of the energy model EnergyPLAN helped formulate a long-term energy scenario for the Jiangsu province in China, based on wholly renewable energy sources, including calculations on the socioeconomic costs on the proposed scenarios at the provincial level.

29. Pedroli B, Elbersen B, Frederiksen P, Grandin U, Heikkilä R, Krogh $\mathrm{PH}$, et al. Is energy cropping in Europe compatible with biodiversity?Opportunities and threats to biodiversity from land-based production of biomass for bioenergy purposes. Biomass Bioenergy. 2013;55:7386. Studies of Belgium, Denmark, Finland, Netherlands, Sweden and Slovakia determined the effect of EU 2020 targets for renewable energy on biodiversity conservation and found that adverse effects may occur related to monoculture, soil and hydrological disturbance, peat overexploitation, and loss of grassland and other ecological sensitive areas. The sustainable management of energy cropping requires careful land-use planning.

30. Lupp G, Steinhauesser R, Starick A, Gies M, Bastian O, Albrecht J. Forcing Germany's renewable energy targets by increased energy crop production: a challenge for regulation to secure sustainable land use practices. Land Use Policy. 2014;36:296-306. The political trends and legal frameworks were shown to impact ecosystems services and therefore, the sustainable use of land

31. Bao C, Fang CL. Geographical and environmental perspectives for the sustainable development of renewable energy in urbanizing China. Renew Sust Energ Rev. 2013;27:464-74. A spatial analysis of the distribution of renewable energy potentials across China, thereby serving to highlight the role of individual regions in developing their own energy potential — solar, wind, hydro, geothermal.

32. Mondol JD, Koumpetsos N. Overview of challenges, prospects, environmental impacts and policies for renewable energy and sustainable development in Greece. Renew Sust Energ Rev. 2013;23: 431-42. An analysis of the Aegean islands in Greece, with regards to energy potentials, energy policies, and building development, highlighted the need for the development and planning of autonomous, non-grid networks.

33. Blaschke T, Biberacher M, Gadocha S, Schardinger I. 'Energy landscapes': meeting energy demands and human aspirations. Biomass Bioenergy. 2013;55:3-16. A top-down methodology employing GIS techniques had mapped the biomass energy potentials in regions in Austria and Germany, to include ways to mediate between landscape types to meet energy demands as well as other eco-system services.

34. Milbrandt AR, Heimiller DM, Perry AD, Field CB. Renewable energy potential on marginal lands in the United States. Renew Sust Energ Rev. 2014;29:473-81. Geospatial data helped the positioning and electrical generation potential from photovoltaics and concentrated solar panels on marginal lands. However, the scale of the project resulted in generalized land categories that do not account for areas such as degraded forests and sensitive ecological areas.

35. Ruiz-Romero S, Colmenar-Santos A, Gil-Ortego R, Molina-Bonilla A. Distributed generation: the definitive boost for renewable energy in Spain. Renew Energy. 2013;53:354-64. On the basis of European research projects on micro-grids, the development of distributed generation was impacted by economic legislation.

36. Stigka EK, Paravantis JA, Mihalakakou GK. Social acceptance of renewable energy sources: a review of contingent valuation applications. Renew Sust Energ Rev. 2014;32:100-6. A focus on Greece's energy policies revealed that their impact on public attitudes relied upon their ability to show the financial contributions, the economic compensation, and benefits from investment in renewable energy. The identification of the different types of green consumers would be important in the development of policies that targeted specific sectors of society.

37. Fast $\mathrm{S}$. A Habermasian analysis of local renewable energy deliberations. J Rural Stud. 2013;30:86-98. Habermas' social theory was employed to analyze the discourse between organizations and the general public when discussing the implementation of renewable energy technologies, which affirmed the author's belief that this method can improve communication and the level of understanding between parties.

38. Wiedman J, Beach T. Distributed generation policy: encouraging generation on both sides of the meter. Electr J. 2013;26(8):88-108. A review of policies on distributed generation in the United States revealed a range of positive tools available to local, state, and federal decision-makers to promote their expansion.

39. Ming Z, Ximei L, Na L, Song X. Overall review of renewable energy tariff policy in China: evolution, implementation, problems and countermeasures. Renew Sust Energ Rev. 2013;25:260-71. By tracing the development changes and barriers to implementation with regards to the renewable energy policies, two specific areas were targeted to be critical for improvement besides the feed-in tariff policy: the grid connection expenses and tariff surcharge subsidies.

40. Noll D, Dawes C, Rai V. Solar Community Organisations and active peer effects in the adoption of residential PV. Energy Policy. 2014;67:330-43. Solar Community Organisations existing in the period between 1970 and 2012 were used to determine how pressure from community peers induced the adoption of photovoltaics in communities.

41. Li LW, Birmele J, Schaich H, Konold W. Transitioning to community-owned renewable energy: lessons from Germany. Procedia Environ Sci. 2013;17:719-28. An analysis of the town of Freiamt, Germany, found that community involvement in the planning process helped increase acceptance for community-owned renewable energy projects, but if similar participation frameworks were to be applied to other towns, an understanding of the differences between rural and urban communities would be needed.

42. Sovacool BK. Expanding renewable energy access with pro-poor public private partnerships in the developing world. Energy Strat Rev. 2013;1(3):181-92. A 5P or pro-poor public-private partnership model was illustrated through eight projects around the world, and compared with eight case studies from the developing countriesChina, Bangladesh, Indonesia, Nepal, Zambia, Laos, India, and Sri Lanka. The study revealed the ability of the $5 \mathrm{P}$ model to withstand or overcome barriers experienced by private companies and utilities when investing in renewable energy in rural areas, thereby focusing not just on RES technologies but also in the provision of energy services.

43. Moula MME, Maula J, Hamdy M, Fang T, Jung N, Lahdelma R. Researching social acceptability of renewable energy technologies in Finland. Int J Sust Built Environ. 2013;2(1):89-98. A survey of 50 people from the towns of Helsinki, Espoo, and Vantaa, Finland, were interviewed to determine their awareness of RES; results indicated that while cost remained a concern, the real issue concerned understanding the differences of perception of RES between the different age groups.

44. Liu D, Shiroyama H. Development of photovoltaic power generation in China: a transition perspective. Renew Sust Energ Rev. 2013;25: 782-92. In transitioning to a renewable economy, the role of 
photovoltaics is systematically analyzed to find that phasing for solar PV would challenge the existing PV industry as well as the different organisations and levels of government that currently have different priorities and degrees of support for the industry.

45. Lo K. A critical review of China's rapidly developing renewable energy and energy efficiency policies. Renew Sust Energ Rev.
2014;29:508-16. On the basis of reviewing energy policies for electricity, industry, transportation, buildings, and local government, Lo determined that these were not sufficient to target specific stakeholders such as small businesses, or to engender the trust needed in the development of independent energy services companies other than the established utilities. 